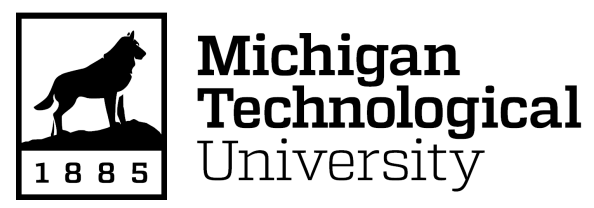

Michigan Technological University Digital Commons @ Michigan Tech

$1-2004$

\title{
Empirical study of QS-9000 using principal components analysis and robust regression
}

Dana M. Johnson

Michigan Technological University, dana@mtu.edu

Follow this and additional works at: https://digitalcommons.mtu.edu/business-fp

Part of the Other Business Commons

\section{Recommended Citation}

Johnson, D. M. (2004). Empirical study of QS-9000 using principal components analysis and robust regression. The Quality Management Journal, 11(1), 33-46.

Retrieved from: https://digitalcommons.mtu.edu/business-fp/30

Follow this and additional works at: https://digitalcommons.mtu.edu/business-fp

Part of the Other Business Commons 


\section{Empirical Study of QS-9000 Using Principal Components Analysis and Robust Regression}

\section{Johnson, Dana M}

The Quality Management Journal; 2004; 11, 1; ProQuest Business Collection pg. 33

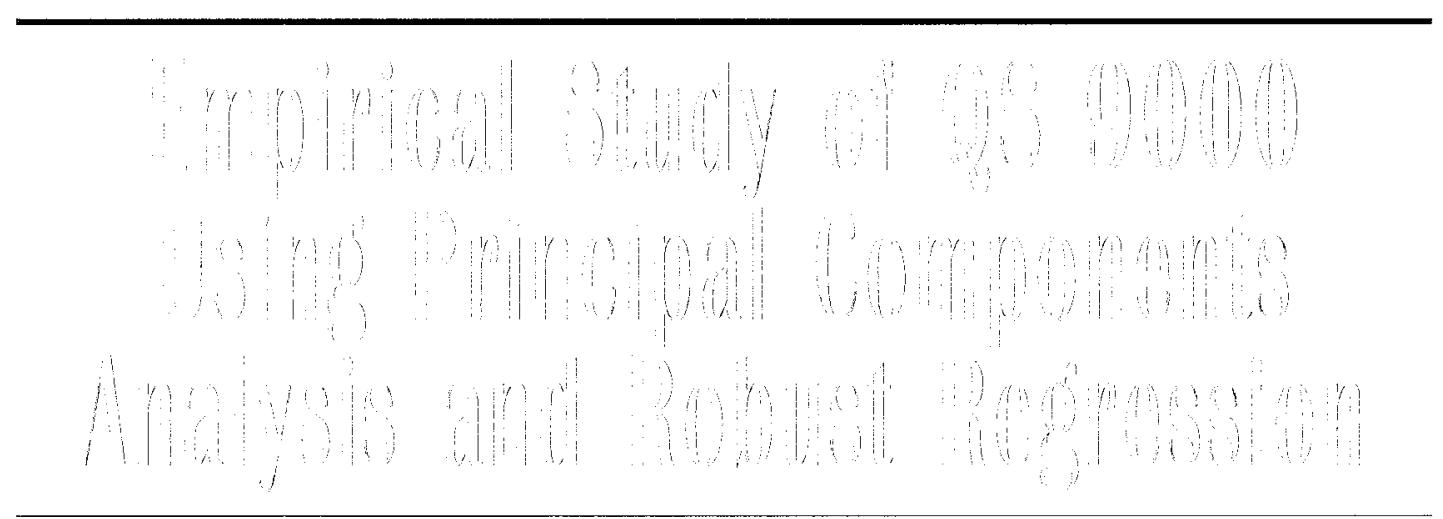

DANA M. JOHNSON, MICHIGAN TECHNOLOGICAL UNIVERSITY

(10) 2004, ASQ

In 1994, the automotive industry took the lead in the development of industry-specific standards to introduce QS-900O (Chryster, Ford, and General Motors 1998). The study presented in this article addresses the impact of organizational variables on both operational and business performance measurement of culomolive suppliers completing QS-9000. A sludy completed by Curkovic, Vikery, and Droge (1999) focused on different aspects of business performance and competitive dimensions of quality as compared to this discussion. Because there is litle empirical research regarding 0S-9000 (Johnson 2001), the literalure revieu included quality management syslems, iso 9000 studies, and organizational variables that impact quality initiatives, and served as a basis for the development of a mail questionnaire. A dalabase with more than 6200 U.S.-based QS-9000 registered locations was used to randomly select 1000 individual locations to receive the mail questionnaire. This study was completed during the summer of 2000 with 153 respondenls. Final resulls suggest that companies are focusing on a fou organizational variables from a bigh-level perspective to prediat operational and business performance. Management supports the QS-9000 change effort by empouering employees lbrough the use of team-based problem-soluing methodologies.

Key words: empirical research, principal componenls analysis, $05-9000$, quality, robust regression

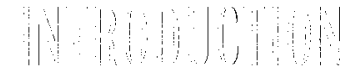

Automotive suppliers are required to obtain quality certification by complying with the automotive quality standard, Quality System Requirements or QS-9000, as a way to ensure their suppliers have a quality system in place to provide a quality product, delivered on time, and at a low cost (Chrysler; lord, and General Motors 1998). QS-9000 includes the international quality standard ISO 9000 and specific automotive-related requirements for DaimlerChrysler, Ford, General Motors, and other original equipment manufacturers (OEMs). However, all suppliers that have attained QS-9000 certification have not consistently achieved the objectives of quality, delivery, and cost. The study presented in this article identified and evaluated the relationships between organizational variables and operational performance measures such as quality and delivery and business performance measures such as cost, sales growth, and customer satisfaction, and whether performance was affected after QS-9000 certification. Key organizational variables and dimensions were identified by review of QS-9000 and related 1 SO 9001 empirical studies.

Many statistical technicues can be applied to gain a better understanding of the predictability of the impact of organizational variables on key measurements. Because there are numerous organizational variables and related dimensions associated with implementing a quality management system to meet QS-9000 registration requirements, it is necessary to statistically reduce the number of independent variables through al data reduction technique. 
Using a data reduction technique such as principal components analysis allows a researcher to discover the latent (unobserved) variables associated with the quality management system. Unless these latent variables are linked to dependent variables, however, a predictive model cannot be identified. When there is a large variation in the responses to survey questions as calculated by the standard deviation, it is useful to apply a statistical technique that takes into consideration this variation or outliers without eliminating them from the model. Robust regression uses a weighted approach to minimize the effects of response variation in dependent variables.

The details of the study are presented in the following order: 1) an overview of the relevant literature associated wifl organizational variables; 2 ) discussion of key operational and business performance measurements; 3) an overview of the methodology; 4) discussion of the results identifying the relationships between organizational variables and performance measurements; and 5) conclusions and recommendations for future research.

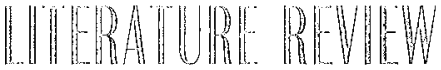

\section{Mpgsanizadicnual Vaniables and Dimensions}

The starting point for identifying key organizational variables, and operational and business performance measures was QS-9000. After primary organizational variables were identified, related literature for the past 10 years was also reviewed to narrow the selected organizational variables and dimensions (see Table 1). The initial organizational variables include leadership for quality, quality strategy, structure for quality management, quality technology/tools, quality culture, and quality rewards/recognition. The term quality was added to further focus on variables that may have a larger, more expansive role in a business entity.

\section{Leadership for quality}

Management responsibility, the first requirement in QS-9000, forms the backbone of the quality system
(Pathius 1997). However, a more appropriate description in a unionized environment such as the automobile industry is "leadership for quality," denoting a partnership between management and union leadership (Carman 1993). The literature reveals several aspects of the decision-making process that either explicitly or implicitly support the use of the term "leadership for quality." Several studies emphasized worker involvement and empowerment as part of the leadership dimension (Spencer 1994; Clements, Sidor, and Winters 1996; McLagan and Nel 1996; McQuater, Dale, and Boaden 1996.) More important, if leadership uses QS-9000 in its business plan, usually leadership supports QS-9000 as a major strategic initiative (Taylor 1996; Recardo 1995; Merdinger 1993; Miller and Cangemi 1993; Vinzant and Vinzant 1996; Shandler and Egan 1994; Ahire, Golhar, and Waller 1996).

\section{Quality strategy}

Leadership sets the stage for planning associated with QS-9000 and its integration into the overall business strategy by accepting responsibility to implement a strategy for identifying, developing, and attaining key goals (Mandal, Howell, and Sohal 1998; Shin, Kalinowski, and El-Enein 1998). In the implementation of QS-9000, business improvement goals must be developed and executed closely with the standard's requirements (Lovitt 1996). Several companies that were successful in their attempts to implement quality management systems had goals and objectives that were clearly linked to the overall business strategy (Jacob 1993). In addition, communicating a clear vision of the change is the responsibility of top management in achieving QS-9000 registration (Recardo 1995; Schriefer 1998). Once the quality plan is formulated and integrated, the organizational structure will need to be adapted to achieve the strategy.

\section{Structure for quality management}

After establishing the quality strategy and integrating it into the overall business plan, the organization's architecture needs to be modified to support the change effort (Recardo 1995). Self-directed, teambased problem solving is a way to continuously 
improve performance. Several QS-9000) requirements confirm that the team structure is the preferred approach to problem solving (Chrysler, liord, and General Motors 1998). Juran (1989) suggests a steering committee and team-based structure with the quality department as the lead. Using team-based problem solving may require that companies switch to self-directed work teans to support the change effort (Recardo 1995). Jobs and processes may need to be redesigned and changed in order to break down departmental barriers, and increase employee involvement, communication, and team-based problem solving (Blackburn and Rosen 1993).

\section{Quality technology/tools}

QS-9000 identifies many tools intended to improve quality. Chief among these is the use of statistical process control (SPC). One explanation for its success is that the process of collecting data and plotting points on charts causes supervisors and workers to pay attention to quality (Kano 1993). In addition, Siegel and Seidler (1996) state that training must be viewed as a part of the key strategy, not as an occasional event. Initial training should include instruction in team formation, problem solving, and group decision making (Bowen and Lawler 1992). 'lo support the move from an individualistic approach to a teambased approach often requires a cultural change, which entails tackling problems of nonconformance to specification or requirements from a multidisciplined perspective (Chrysler, Ford, and General Motors 1998).

\section{Quality culture}

Getting multidisciplinary project teams to work well together in traditional, functional cultures is difficult and poses problems in communication, reaching consensus, and implementing decisions (Schein 1996; Thompson 1998). In manufacturing, teams are primarily made up of operators. Schein (1996) states that operator culture is based on human interaction and requires a high level of communication, trust, and teamwork to accomplish work. 'There may be an apparent conflict between empowering individual workers and autonomous work groups with the articulation of standardized process and procedures imposed by QS-9000 and ISO 9000 ('Juckman 1994). $\Lambda$ study by Mallak and Kursted (1996) addressing the culture gap when managing an organization change found that higher levels of employee commitment to organizational changes, such as a quality improvement program, corresponded with a culture that included recognition for performance and opportunities for professional development.

\section{Quality reward and recognition}

An apparent conflict occurs between the articulations of the empowerment of individuals or autonomous work groups with the imposition of quality standards like QS-9000 and ISO 9000 (luckman 1994). In addition, getting multidisciplinaly project teams to work well together in cultures that have traditionally functioned under hierarchical systems poses problems for communication, consensus reaching, and decision implementing (Schein 1996; 'l'hompson 1998). In manufacturing, teams are primarily made up of machine or assembly operators and managers, who comprise a culture based on human interaction that requires a high level of communication, trust, and teamwork (Schein 1996). For this reason, employees are more likely to commit to the kinds of organizational changes required of quality improvement programs, if those cultures include recognition for performance and opportunities for professional development (Mallak and Kursted 1996).

\section{Operational Performance}

Because researchers consistently ayree about what constitutes operational performances associated with improved cuality and improved on-time delivery performance, this study limited its information gathering to these two operational measures. Past quality performance constitutes an important contextual variable against which to compare the present level of an organization's quality management practices (Benson, Saraph, and Schroeder 1991; Ahire 1996). Outcomes can best be defined as the results of the organization's work in achieving a desired goal (McNabb and Sepic 1995). 
Figure 1 Initial model.

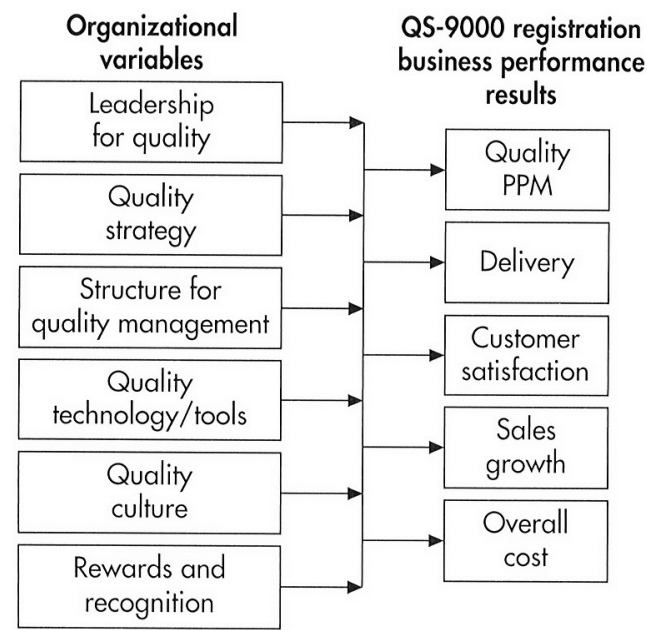

QS-9000 requires a business plan that includes quality, cost, customer satisfaction, and key internal quality and operational performance measurements (Chrysler, Ford, and General Motors 1998). Ultimately, operational performance has an impact on business performance and also gains significant attention.

\section{Business Performance}

Quality management practices impact numerous business performance measures, and care must be taken to choose measures that apply universally to most situations. Several asset-related measures have been investigated, such as return on assets and return on investment (Curkovic, Vickery, and Droge 1999). However, asset-related measures vary so significantly among different industries (that is, steel, plastics, chemicals, and so on) and among those with new technology compared to old technology, that these measures are poor choices. Some companies reported increases in market share, sales growth, and customer satisfaction, and a decrease in costs as a result of becoming QS-9000 certified (AIAG 1998). Similar studies compare the performance outcomes associated with operational and business measures to judge the effectiveness of quality management systems. Adam (1994) focused on the impact of performance quality and financial performance to develop a model to predict quality improvement. Skrabec (1999) identified the underlying model components through factor analysis and then applied structural equation modeling to study system effectiveness as measured by market share and product quality. This QS-9000 study focused on determining whether organizational variables are predictors of operational and business performance.

Using the information gathered from the literature review, a graphic representation of the initial model is presented in Figure 1.

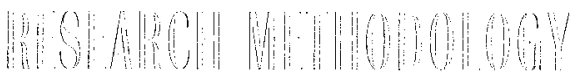

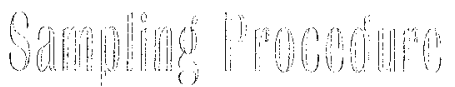

To select participants for the study, the American Society for Quality database for all QS-9000 registered companies was reduced to organizations located in the United States. This sampling frame included all U.S. automotive suppliers holding QS-9000 registration. The unit of analysis was each separate location listed in the database. From these approximately 6200 locations, a random sample of 1000 was selected for participation in the survey.

Surveys were sent to key informants, defined as quality directors, managers, or coordinators with primary responsibility for QS-9000, because they were deemed to be the most knowledgeable of practices associated with QS-9000. The interview questionnaire had been used in an earlier study (Johnson 1999). Prior to the initial study, quality directors and managers of a large, tier-one automotive supplier participated in the pretest and validated for face validity. A letter explaining the purpose of the study was included with the questionnaire. The respondents were promised a copy of the results as an incentive to respond. Of the 1000 organizations contacted, 153 returned their surveys. This may seem like a small number, but the results collaborated those of an earlier study using the same questionnaire (Johnson 1999).

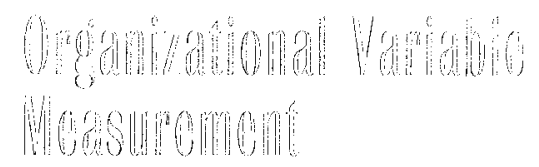

As noted in Table 1, dimensions further defined the organizational variables. The organizational 
dimensions were translated into attitudinal statements. Using a five-point Likert scale, respondents were asked about their agreement with the particular statement with the endpoints "strongly disagree" (1) and "strongly agree" (5). This was used to determine whether organizational dimensions factored into the pursuit of QS-9000 and to what degree. (See the Appendix for further details of the survey questions 1-34.)

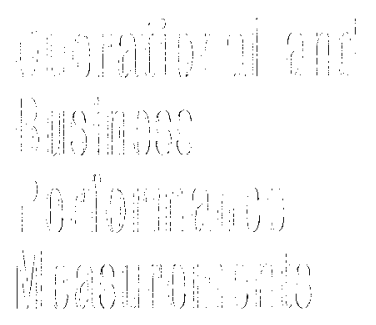

Again respondents used a fivepoint likert scale and were asked about their agreement with the particular statement with the endpoints "strongly disagree" (1) and "strongly agree" (5). Operational performance was evaluated using two common measures: quality and delivery. Business performance measures were customer satisfaction, sales growth, and impact on overall costs. (See the Appendix for further details of the survey questions 35-39.)

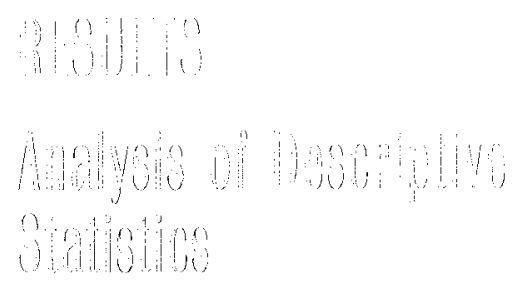

The purpose of analyzing the descriptive statistics relating to the performance measures was to gain a preliminary understanding of the benefits or gains

\begin{tabular}{|c|c|}
\hline Initial organizational variables & Related dimensions \\
\hline Leadership for quality & $\begin{array}{l}\text { - Leadership uses QS-9000 to develop business strategy } \\
\text { - Supervisor approval of decision } \\
\text { - Decisions made at lowest levels } \\
\text { - Team members' opinions and ideas before decision } \\
\text { - Leadership support of QS-9000 } \\
\text { - Emphasize worker involvement }\end{array}$ \\
\hline Quality strategy & $\begin{array}{l}\text { - Managers plan for changes related to QS-9000 } \\
\text { - Quality goals and objectives - business plan } \\
\text { - QS-9000 integrated with business plan } \\
\text { - Senior management communicates vision }\end{array}$ \\
\hline Structure for quality management & $\begin{array}{l}\text { - Quality department responsibility for QS-9000 } \\
\text { - Jobs and processes redesigned } \\
\text { - Steering committee-QS-9000 } \\
\text { - Self-directed work teams } \\
\text { - Problems solved in small group sessions } \\
\text { - Employees work together to solve problems }\end{array}$ \\
\hline Quality technology/tools & $\begin{array}{l}\text { - Charts posted near shop floor } \\
\text { - Data and facts used in problem solving } \\
\text { - Production stopped for quality problems } \\
\text { - Track supplier performance } \\
\text { - Use of statistical methods } \\
\text { - QS-9000 training }\end{array}$ \\
\hline Quality culture & $\begin{array}{l}\text { - Sufficient communication on QS-9000 } \\
\text { - Employees focus on customer satisfaction } \\
\text { - Face-to-face discussion with senior management } \\
\text { - Open communication without fear of punishment } \\
\text { - Encourage suggestions } \\
\text { - Communication between departments } \\
\text { - Employees trusted to perform job }\end{array}$ \\
\hline Quality rewards and recognition & $\begin{array}{l}\text { - Recognition for the quality of work } \\
\text { - Supervisor reward for cooperation } \\
\text { - Supervisor feedback to teams } \\
\text { - Rewards for ideas and suggestions } \\
\text { - Rewards for quality improvement }\end{array}$ \\
\hline
\end{tabular}

achieved as a result of QS-9000 registration. 'The median, mean, and standard deviation for the operational and business performance measures for each dimension are displayed in 'lable 2 . In reviewing the data, for all but one of the questions, the data are skewed to the left with the median greater than the mean. In comparing the five measures, customer satisfaction has the highest mean at 3.61. However, on a five-point scale the averages are between the neutral (3) and agree (4), which means that companies are not experiencing the expected gains in these selected measures after completing QS-9000. 
Toble 2 Operailonal and business performance measures

\begin{tabular}{l|c|c|c}
\hline Performance measure & Median & Mean & $\begin{array}{c}\text { Standard } \\
\text { deviation }\end{array}$ \\
\hline As a result of QS-9000, our delivery performance has improved. (operational) & 4 & 3.48 & 1.01 \\
\hline $\begin{array}{l}\text { After we completed QS-9000 registration, our overall quality parts per million (PPM) were } \\
\text { reduced. (operational) }\end{array}$ & 4 & 3.44 & 1.16 \\
\hline Our customer satisfaction level has improved since completing QS-9000 registration. (business) & 4 & 3.61 & 0.87 \\
\hline We have experienced sales growth as a result of our QS-9000 registration. (business) & 4 & 3.37 & 1.03 \\
\hline As a result of QS-9000, we have reduced our overall costs. (business) & 3 & 3.08 & 0.98 \\
\hline
\end{tabular}

The purpose of analyzing the descriptive statistics for the organizational dimension-related survey questions was to gain an initial understanding of the organizational variables affected by $0 S-9000$ and to compare prior results for statistical significance. 'l'hese results were compared to the previous study conducted in 1999 (Johnson 2001). $\Lambda$ t-test with $\alpha=0.05$ was used to assess the statistical significance of differences between the sample means for the previous (58 respondents) and the current (153 respondents) responses for all questions and found no statistically significant differences. The means and standard deviations for the organizational dimensions are shown in the Appendix. Principal components analysis was applied to simplify the development of a predictive model.

\section{PRANCIPAI COMPONENT Palsulis}

Principal components analysis is more of a means to an end rather than an end in itself, because it frequently serves as an intermediate step to a much larger investigation and serves as input into multiple regression (Johnson and Wicern 1998; Lynn and McCulloch 2000; Jong and Kotz 1999). Principal components analysis is a tool used for estimation in latent variable models (Lynn and McCulloch 2000); Petroni and Baglia 2000). A limitation of principal components, or latent variables, is that it may be difficult to attach concrete meanings to the factors (Neter et al. 1996). In this particular study it was not an issue because each factor had an apparent meaning.
In this study, there were 34 original dimensions developed from six organizational variables (see Table 1). After principal components analysis using varimax (orthogonal) rotational approach, there were 15 of the original dimensions loaded on six factors (see 'lable 3). The criteria for the number of factors to extract were determined by eigenvalues greater than one and total variance explained of at least five percent. In defining the factors, the factor loadings matrix was examined and factor loadings of \pm .55 were deemed significant becaluse the sample size was greater than 100 (Hair et al. 1998). Principal component analysis allows for exploratory analysis of the dimensions to find if they will load on similar organizational variables as originally identified in the onset of the study. By reviewing the factor descriptions provided in Table 3, there are groupings similar to those described in Table 1 with fewer dimensions, as well as some new combinations.

Based on experience and a review of the literature, it appears that respondents are merely meeting the requirements to achieve QS-9000 without fully institutionalizing all the components of a total quality management system as identified in Table 1. It is encouraging that companies have embraced some of the key concepts, but based on this study, there must be more aspects of a quality management system applied for companies to successfully achieve the desired improvements. The factor scores, from the latent variables, were then used for subsequent analysis and model building using robust regression analysis. 
Tolole 3 Principal componenis andysis resultis.

\begin{tabular}{|c|c|c|c|c|}
\hline $\begin{array}{l}\text { Factor/variables } \\
\text { (question number) }\end{array}$ & Factor description & $\begin{array}{l}\text { Factor } \\
\text { loadings }\end{array}$ & $\begin{array}{l}\text { Cronbach's } \\
\text { alpha }\end{array}$ & $\begin{array}{l}\text { Initial organizational } \\
\text { variable (Figure 1) }\end{array}$ \\
\hline Factor 1: & Quality rewards and recognition & & $\alpha=.81$ & \\
\hline QRRQI-Rewards for quality improvement (7) & & -0.837744 & & $\begin{array}{l}\text { Quality rewards and } \\
\text { recognition }\end{array}$ \\
\hline QRRIS-Rewards for ideas and suggestions (14) & & -0.749385 & & $\begin{array}{l}\text { Quality rewards and } \\
\text { recognition }\end{array}$ \\
\hline $\begin{array}{l}\text { QRRCTP-Supervision rewards } \\
\text { for cooperation (18) }\end{array}$ & & -0.683450 & & $\begin{array}{l}\text { Quality rewards and } \\
\text { recognition }\end{array}$ \\
\hline Factor 2: & Leadership direction & & $\alpha=.76$ & \\
\hline $\begin{array}{l}\text { QUALSV - Senior management communicates } \\
\text { vision (3) }\end{array}$ & & 0.767813 & & Quality strategy \\
\hline LEADS－Leadership supports QS-9000 (1) & & 0.693000 & & Leadership for quality \\
\hline Factor 3: & Employee empowerment & & $\alpha=.79$ & \\
\hline $\begin{array}{l}\text { QTTDF-Data and facts used in problem } \\
\text { solving }(16)\end{array}$ & & -0.675287 & & Quality technology/tools \\
\hline QCULT-Employees trusted to perform job (27) & & -0.618495 & & Quality culture \\
\hline Factor 4: & Quality tools & & $\alpha=.75$ & \\
\hline QTTC-Charts posted near shop floor (13) & & -0.749100 & & Quality technology/tools \\
\hline QTTSM-Use of statistical methods (28) & & -0.666631 & & Quality technology/tools \\
\hline Factor 5: & Quality culture & & $\alpha=.75$ & \\
\hline LEADLL — Decisions made at lowest level (12) & & -0.698295 & & Leadership for quality \\
\hline $\begin{array}{l}\text { QCULFP-Open communication without } \\
\text { fear of punishment (19) }\end{array}$ & & -0.626483 & & Quality culture \\
\hline Factor 6: & Structure for quality management & & $\alpha=.82$ & \\
\hline $\begin{array}{l}\text { STRUCSG_-Problems solved in small } \\
\text { group sessions (2) }\end{array}$ & & -0.667908 & & $\begin{array}{l}\text { Structure for quality } \\
\text { management }\end{array}$ \\
\hline $\begin{array}{l}\text { STRUCR-Quality department responsible } \\
\text { for QS-9000 (22) }\end{array}$ & & -0.628131 & & $\begin{array}{l}\text { Structure for quality } \\
\text { management }\end{array}$ \\
\hline
\end{tabular}

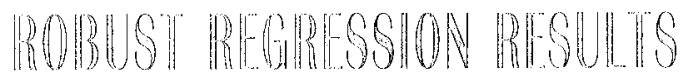

In studying relationships between organizational dimensions and operational and business performance, several of the existing studies utilized factor or principal components analysis and identified relationships (Adam, 1994; Ahire, Golhar, and Waller 1996; Benson, Saraph, and Schroeder 1991; Berry 1996; Fibrahimpour and Cullen 1993; Foster and Adams 1996; Skrabec 1999; Waller and Nhire 1998). Since the goal of principal component analysis is to reduce the number of variables (Johnson and Wicern 1998; Petroni and Baglia 2000; Tarpey 1999; Su and 'long 1997), once the different dimensions (variables) have loaded on the factors, the factor scores can be used as a means to develop a predictive model using regression techniques. 


\begin{tabular}{|c|c|c|c|c|c|}
\hline $\begin{array}{l}\text { Operational or business } \\
\text { performance measurement }\end{array}$ & $\begin{array}{l}\text { Model } \\
\text { p value }\end{array}$ & $\mathrm{R}^{2}$ & $\begin{array}{l}\text { Adjusted } \\
\mathrm{R}^{2}\end{array}$ & Factors included in the model & $\begin{array}{l}\text { Beta } \\
\text { coefficient }\end{array}$ \\
\hline Delivery & .0001 & .340 & .321 & $\begin{array}{l}\text { Quality rewards and recognition, leadership } \\
\text { direction, employee empowerment, structure } \\
\text { for quality management }\end{array}$ & 3.745 \\
\hline Quality & .0002 & .328 & .309 & $\begin{array}{l}\text { Quality rewards and recognition, employee } \\
\text { empowerment, quality tools, structure for } \\
\text { quality management }\end{array}$ & 3.810 \\
\hline Customer satisfaction & .0005 & .446 & .427 & $\begin{array}{l}\text { Leadership direction, employee empowerment, } \\
\text { quality tools, quality culture, structure for } \\
\text { quality management }\end{array}$ & 3.725 \\
\hline Sales growth & .0001 & .409 & .388 & $\begin{array}{l}\text { Quality rewards and recognition, leadership } \\
\text { direction, employee empowerment, quality } \\
\text { culture, structure for quality management }\end{array}$ & 3.476 \\
\hline Cost & .0030 & .361 & .334 & $\begin{array}{l}\text { Quality rewards and recognition, leadership } \\
\text { direction, employee empowerment, quality tools, } \\
\text { quality culture, structure for quality management }\end{array}$ & 3.193 \\
\hline
\end{tabular}

There are various forms of regression that can be used for multivariate analysis and include multiple, step-wise, and robust regression techniques. Robust regression provides an alternative to least squares regression that works with less restrictive assumptions (Hintze 1998). Draper and Smith $(1981,342)$ state that even if the distribution is normal, outliers may occur, that is, observations atypical of the usual normal distribution, perhaps with different means, or from a normal distribution with somewhat larger variance. In some cases it may be possible to discard the outliers and continue with model development. However, when outliers affect different observations for different dimensions, the data set may dwindle to the point where there are insufficient data to complete a thorough analysis (Neter et al. 1996). Analysis of outlying influential cases may lead to valuable insights for strengthening the model such that the outlying cases are no longer outliers but accounted for by the model (Neter et al. 1996).

When using robust regression, users must be familiar with the variables they are using to understand the impact of outliers and also the final model outcome. Because the principal components (factors) in this study have a natural intuitive meaning, it is
Figure 2 Revised model

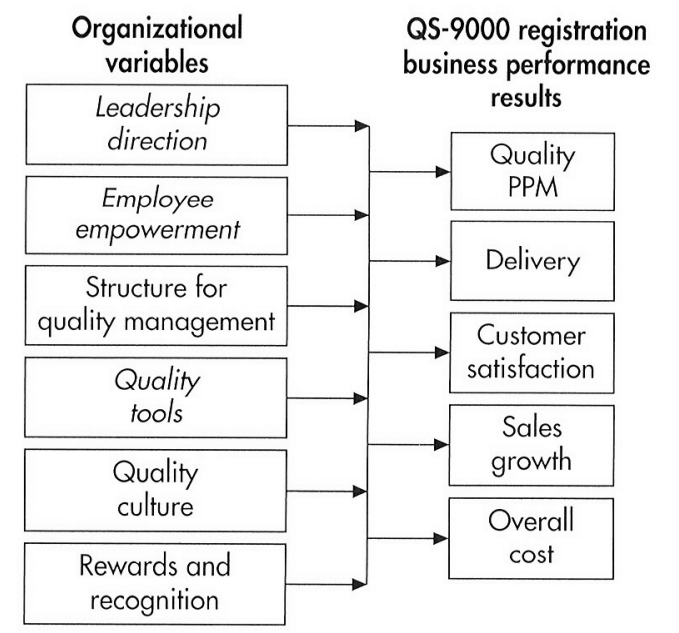

best to leave the regression equation expressed in terms of the components (Neter et al. 1996). All models were significant at $\mathrm{p}<0.05$. All of the coefficients, including the intercept, for each of the models in Table 4 are statistically significant at a p-value $<0.05$. All factors appeared in at least one of the models.

Each performance measure is affected by a different set of organizational factors, meaning some factors have a greater impact on some performance 
measurements than others. 'The models are summarized in Table 4. The initial graphic representation of the model was revised to include the modified organizational variable descriptions based on the principal components analysis (see Figure 2).

\section{$31010: 10$}

Based on the results in Table 3, the goal to reduce the dimensionality by using principal components analysis was achieved. In this exploratory study, the number of organizational dimensions loading on six factors was surprisingly small. It was expected that a greater number of dimensions associated with quality standards and certification would have loaded on the six factors. There were 34 organizational dimensions defined from six organizational variables (see Table 1). Through the use of principal component analysis, 13 organizational dimensions were loaded on six factors. In reviewing the dimensions loaded on factors, several of the original organizational variables were renamed to be more reflective of the combinations (see Table 3 and Table 4). Although several of the factor loadings are negative, the absolute factor loadings form the basis for labeling or interpreting the factor (Hair et al. 1998). Once the factors are defined (see Table 3), then it is important to compare the proposed outcome and the results.

The leadership for quality organizational variable was renamed leadership direction because it was not as encompassing as the initial intent. Also, quality strategy did not appear to be a proper description for any of the factors and a new description of employee empowerment emerged. Regarding the implementation and institutionalization of QS-9000, there are major issues with companies that do not focus on leadership for quality and quality strategy as these organizational variables serve as the foundation. As stated earlier by Pathius (1997), management responsibility is the backbone of the quality system. It appears from the survey results that management supports QS-9000 but has not likely integrated quality with the business strategy. Organizations may be overemphasizing achievement of registration to the detriment of other important business issues (Halachemi 1996). Since the foundation of leadership and strategy are not strong, it is nol surprising that the slructure for quality management is not well developed. Interestingly, both the quality department and team-based focus were present in the model. Other aspects of structure, such as steering committee and redesign of jobs and processes, were not significantly correlated to load on the factor relating to structure. Information, data, and facts are important in the team-based problem-solving process with few variables loading on the quality tools factor. When team-based problem solving is used, employees need to be empowered to make decisions at the lowest level in the organization (Spencer 1994). Along with team-based processes, the reuards and recognition component is important. Rewerds and recognition variables were negatively correlated with the factor and in analyzing the sample means for individual questions, it appears that this is similar to other initiatives where companies are not using rewards and recognition to change behavior (Lawler 1996).

When the results from principal components analysis serve as input for further multivariate analysis, there are several approaches that can be used. If there is one variable that has a higher absolute factor loading, the raw data from this variable should be used as input for further analysis. However, it is better to use either factor scores or raw data (that is, Likert-scaled data) to avoid complexity (Hair et al. 1998) in model development. Since no single variable "represents" each factor or component, then factor scores are more appropriate and were included for further analysis using robust regression (Hair et al. 1998). The dimensionality of each scale is supported by the "clean" interpretation of each factor, with high factor loadings of each variable on only one factor (Hair et al. 1998, 129). An important consideration when constructing summated scales is the positive and negative loadings. The variables with negative loadings are reverse scored so that the correlations and the loadings are now all positive with the factor; reverse scoring is the process by which the data values for a variable are reversed so that its correlations with other variables are reversed (fiair et al. 1998, 130). 
Once the principal components (factors) were analyzed, the reverse factor scores served as input into robust regression modeling. Statistically significant models, with $\mathrm{p}<0.05$, were developed for each of the dependent variables of operational and business performance. 'the coefficient of determination ( $\mathrm{R}^{2}$ ) for models range from 340 to .446 . Although it may be desirable to have a higher $\mathrm{R}^{2}$ value, during initial development lower values are acceptable. Even in using a method like robust regression, which down weights outlying observations, some outliers can still be eliminated from the analysis. For each of the models, out of the 153 observations, between five and eight observations were removed in formulation of the final model.

Although there are models identified for each of the dependent operational or business performance measures, in analyzing the sample means of all variables there is a need for more emphasis on quality dimensions and improvement in performance measures to truly integrate quality certification like QS-9000 into the mainstream business practices and strategy.

The research shows that organizational dimensions have some impact on operational and business performance measures after completing QS-9000 registration. This study confirmed suspicions that companies were not achieving the desired results in operational and business performance measures as noted in 'lable 2 . This is counter to what is presented in the introduction to QS-9000 document and the 1998 AIAG study (Chrysler, lord, and General Motors 1998; AIAG 1998).

Companies have experienced positive movement toward institutionalizing change in their organizations. As the models demonstrated, management supports QS-9000 implementation. In fact, employees feel empowered to participate in teams to facilitate the efforts. In early stages of quality systems implementation, the quality department usually takes the lead, as confirmed by this study. The respondents indicated that there is strong team-based problem solving using information, data, and facts.
In reviewing the literature based on change management, the focus for institutionalizing change is on the human element (Kotter 1996). Since this study represents a snapshot in time, long-term analysis is necessary as companies sustain their QS-9000 registration. 'There are numerous responses to the survey that support the fact that those criteria, which are necessary for long-term, sustained change, are not in place.

T'he sample means from the 2000 study confirmed the results of the 1999 study using the same survey questions and finding no statistically significant differences between the two years. Because of the changing nature of the automotive quality system requirements, and the movement to ISO/TS 16940:2002, it may be advantageous to revisit the initial survey and in place of QS-9000, indicate the new standard. The organizational variables identified in this study could also be used for companies completing the ISO 9001 certification process. It is believed that if the survey would have been completed in 2001, the results may not have been different, and other issues, such as the economy, would have an impact on the survey results.

\section{REFERENCES}

Adam, E. E., Jr. 1994. Alternative quality improvement practices and organization performance. Journal of Operations Management 12, no. 1: 27-44.

Ahire, S. L. 1996. An empirical investigation of quality management in small firms. Production and Inventory Management Journal 35 , no. 4: 44-50.

Ahire, S. L., D. Y. Golhar, and M. A. Waller. 1996. Development and validation of TQM implementation constructs. Decision Sciences 27, no. 1: 23-56.

AIAG. Automotive Industry Action Group. 1998. Annual Quality Survey Report, Southfield, Mich.: AIAG.

Benson, P. G., J. V. Saraph, and R. G. Schroeder. 1991. The effects of organizational context on quality management: an empirical investigation. Management Science 37 no. 9: 1107-1124.

Berry, R. W. 1996. An investigation of the relationship between world class quality system components and performance (total quality management). Abstract in Dissertation Abstracts International.

Blackburn, R., and B. Rosen. 1993. Total quality and human resource management: lessons learned. Academy of Management Executives 7, no. 3: 49-66. 
Bowen, D., and E. E. Lawler III. 1992. Total quality oriented human resource management. Organization Dynamics 20, no. 4: $29-41$.

Carman, J. M. 1993. Continuous quality improvement as a survival strategy: The Southern Pacific experience. California Management Review 35, no. 3: 118-132.

Chrysler Corporation, Ford Motor Company, and General Motors Corporation. 1998. Quality systems requirements, QS-9000, 3rd ed. Southfield, Mich.: Automotive Industry Action Group.

Clements, R., S. M. Sidor, and R. E. Winters. 1996. Preparing your company for QS-9000. Milwaukee: ASQ Quality Press.

Curkovic, S., S. K. Vickery, and C. Droge. 1999. Quality and business performance: An empirical study of first-tier automotive suppliers. Quality Management Journal 6, no. 2: 29-40.

Draper, N., and H. Smith. 1981. Applied regression analysis, 2nd edition. New York: John Wiley \& Sons, Inc.

Ebrahimpour, M., and J. B. Cullen. 1993. Quality managemen in Japanese and American firms operating in the United States: A comparative study of styles and motivational beliefs. Management International Review 33, no. 1: 23-38.

Foster, S. T., and E. E. Adams. 1996. Examining the impact of speed of quality improvement on quality-related costs. Decision Sciences 27, no. 4: 623-646.

Hair, J. F., R. E. Anderson, R. L. Tatham, and W. C. Black. 1998. Multivariate data analysis. Upper Saddle River, N.J.: Prentice Hall.

Halachemi, A. 1995. The pros and cons of participating in a quality award program. National Productivity Review 15, no. 1 : $87-100$.

Hintze, J. L. 1998. NCSS 2000 reference manuals. Kaysville, Utah: Number Crunching Statistical Systems.

Jacob, R. 1993. TQM: More than a dying fad? Fortune 128, no. $9: 66-69$

Johnson, D. M. 2001. Linking QS-9000 to quality performance outcomes. TQM Magazine 13, no. 3: 161-168.

Johnson, D. M. 1999. Organizational and quality performance change following achievement of $Q S-9000$ registration: An event study. Detroit.: Wayne State University.

Johnson, J. G. 1992. Rewarding the right behaviors. Tapping the Network Journal 3, no. 3: 21-24

Johnson, R. A., and D. W. Wichern. 1998. Applied multivariate statistical analysis. Upper Saddle River, N.J.: Prentice Hall.

Jong, J. C., and S. Kotz. 1999. On a relation between principal components and regression analysis. The American Statistician 53, no. $4: 349-352$.
Juran, J. M. 1989. Juran on leadership for quality. New York: The Free Press.

Kano, N. 1993. A perspective on quality activities in American firms. California Management Review 35, no. 3: 12-31.

Kotter, J. P. 1996. Leading change. Boston: Harvard Business School Press.

Lawler, E. E. 1996. From the ground up. San Francisco: JosseyBass.

Lovit, M. 1996. Continuous improvement through the QS-9000 road map. Quality Progress 29, no. 3: 39-43.

Lynn, H. S., and C. E. McCulloch. 2000. Using principal components analysis and correspondence analysis for estimation in latent variable models. Journal of American Statistical Association 95, no. 450: 561-572.

Mallak, L. A., and H. A. Kursted, 1996. Using culture gap analysis to manage organizational change. Engineering Management Journal 8, no. 2: 35-41.

Mandal, P., A. Howell, and A. S. Sohal. 1998. A systemic approach to quality improvements: the interaction between the technical, human and quality systems. Total Quality Management 9, no. 1:79-100.

Mclagan, P., and C. Nell. 1996. A new leadership style for genuine total quality. The Journal for Quality and Participation 19, no. 3: 14-16.

McNabb, D. E., and F. T. Sepic. 1995. Culture, climate, and total quality management: Measuring readiness for change. Public Productivity \& Management 18, no. 4: 369-385.

McQuater, R. E., B. G. Dale, and R. J. Boaden. 1996. The effectiveness of quality management tools and techniques: an examination of the key influences in five plants. Professional Instifute of Mechanical Engineers 210: 329-38.

Merdinger, W. J. 1993. Why TQM? A president's perspective. Journal of Management Development 12, no. 7: 32-15.

Miller, R. L., and J. P. Cangemi. 1993. Why total quality management fails: Perspective of top management. Journal of Management Development 12, no. 7: 40-50.

Neter, J., M. H. Kutner, C. J. Nachtsheim, and W. Wasserman. 1996. Applied linear statisfical models. New York: McGraw-Hill.

Pathius, M. 1997. Do you know what QS-TE means? If you make tools or equipment for the Big Three, you should. Manufacturing Engineering: 40-48.

Petroni, A., and M. Baglia. 2000. Vendor selection using principal component analysis. The Journal of Supply Chain Management 36, no. 2: 63-69.

Recardo, R. F. 1995. Overcoming resistance to change. National Productivity Review 14, no. 2: 5-12. 
Robinson, J. P., P. R. Shaver, and L. S. Wrightsman. 1991. Criterio for scale selection and evaluation. In Measures of Personality and Social Psychological Attitudes, eds. J. P. Robinson, P. R. Shaver, and L. S. Wrightsman. San Diego: Academic Press.

Robinson, J. P., and P. R. Shaver. 1973. Measures of psychological attitudes. Ann Arbor, Mich.: Survey Research Center Institute for Social Research, University of Michigan.

Schein, E. H. 1996. Three cultures of management: The key to organizational learning. Sloan Management Review 38, no. 1: 9-20.

Schriefer, A. 1998. The future: Trends, discontinuities, and opportunities. Strategy \& Leadership 26, no. 1: 26-32.

Shandler, M., and M. Egan. 1994. Leadership for quality. The Journal for Quality and Participation 17, no. 2:66-71.

Shin, D., J. G. Kalinowski, and G. A. El-Enein. 1998. Critical implementation issues in total quality management. S.A.M. Advanced Management Journal 63, no. 1: 10-14.

Siegel, G. B., and E. Seidler. 1996. Towards a public service blend of human resource management and TQM. International Journal of Public Administration 19, no. 10: 1781-1810.

Skrabec, Q. R., Jr. 1999. ISO 9000 as a quality assurance system: A theoretical framework (market share, product quality). Abstract in Dissertation Abstracts International.

Spencer, B. A. 1994. Models of organization and total quality management: A comparison and critical evaluation. Academy of Management Review 19, no. 3: 446-471

Su, C. T., and L. I. Tong. 1997. Multi-response robust design by principal component analysis. Total Quality Management 8, no. 6: $409-416$.

Tarpey, T. 1999. Self-consistency and principal components analysis. American Statistical Association 94, no. 446: 456-467.

Taylor, W. A. 1996. Organizational differences in ISO 9000 implementation practices. International Journal of Quality and Reliability 12, no. 7: 10-27.

Thompson, K. R. 1998. Confronting the paradoxes in a total quality environment. Organizational Dynamics 26, no. 3: $62-74$.

Tuckman, A. 1994. The yeilow brick road: Total quality management and the rest. Organizational Studies 15, no. 5: 727-751.

Vinzant, J. C., and D. H. Vinzant. 1996. Strategic management and total quality management: Challenges and choices. Public Administration Quarterly 20, no. 2: 201-219

Waller, M. A., and S. Ahire. 1998. Management perception of the link between product quality and customers' view of product quality. International Journal of Operations \& Production Management 16, no. 9: 23-33

\section{BIOGRAPHY}

Dana M. Johnson is an assistant professor of operations management at Michigan Tech University, Houghton, Michigan. Her research interests include integrating manufacturing initiatives with business strategy, impact of standards implementation and organizational change, environmentaily conscious manufacturing, and lean manufacturing practices. Johnson earned a doctorate in industrial engineering and business administration and a master's of science degree in manufacturing engineering from Wayne State University. She also holds the following certificates: ASQ CQE, CQA, CQMgr; CPA; CMA; and is a Six Sigma Green Belt. Prior to returning to academics, for 15 years Johnson worked primarily within the automotive industry and owned a consulting firm for seven years. Johnson also holds a master of science degree in industrial technology (quality) from Eastern Michigan University, a master's in business administration from Northern Michigan University, and a bachelor of science degree in business administration from Michigan Tech University. She has been published in the International Journal of Operations and Production Management, TQM Magazine, Managerial Finance Journal, Environmental Quality Management Journal, and International Journal of Quality \& Reliability Management. Johnson may be contacted at School of Business and Economics, Michigan Tech, 1400 Townsend Drive, Houghton, MI 49931. 1295; 906-487-2803; fax: 906-487-2944; e-mail: dana@mtu.edu.

\section{APPENDIX}

\section{Sample}

The study focused on automotive suppliers at individual plant locations that have completed QS-9000 registration and did not differentiate between firsttier and lower-tier suppliers. The earlier QS-9000 study surveyed only second-tier automotive suppliers (Johnson 2001) and another study focused on firsttier automotive suppliers (Curkovic, Vickery, and Droge 1999). A database with all worldwide companies that have completed QS-9000 registration was purchased from the American Society for Quality. The database was narrowed to companies in the United States. A random sample of 1000 companies was selected from the survey. For independence, a search was completed to make sure companies that participated in the first study were not included in 


\section{Survey questions}

1. Generally, senior management supports QS-9000 activities.

2. In pursuing and achieving QS-9000 registration, many problems have been solved through small group sessions.

3. Senior management clearly communicates the quality policy and vision.

4. Employees and managers work closely together to resolve quality problems.

5. Supplier performance is regularly charted as it relates to quality and delivery performance.

6. We encourage employees to come forward with ideas and suggestions

7. Workers are rewarded for quality improvements.

8. Production is stopped immediately for quality problems.

9. Our plant emphasizes worker involvement in the achievement of QS-9000 registration.

10. There is good communication between departments in this plant.

11. QS-9000 has been integrated with the overall business planning process.

12. In addressing quality issues, decisions are made at the lowest level that is directly involved.

13. Charts showing defects, schedule compliance, and machine breakdowns are posted near the shop floor.

14. We reward for ideas and suggestions for implementing a QS-9000 quality management system.

Mean

Sid. dev

15. There is sufficient communication about what is going on with QS-9000 at our company.

16. Generally, data and facts are used to identify solutions to quality problems.

17. Training is conducted on a regular basis to support QS-9000 activities.

18. Supervision rewards for being cooperative and a good team player.

19. Within reason, people in this plant can say what they want without fear of punishments.

\begin{tabular}{l|l}
4.21 & 0.89
\end{tabular}

$3.80 \quad 0.80$

$3.93 \quad 0.88$

$3.90 \quad 0.69$

$3.98 \quad 1.07$

4.25

$3.18 \quad 1.24$

\begin{tabular}{l|l}
3.88 & 0.95
\end{tabular}

$\begin{array}{ll}3.99 & 0.78\end{array}$

$3.52 \quad 0.99$

\begin{tabular}{l|l}
3.87 & 0.89
\end{tabular}

$3.39 \quad 0.93$

\begin{tabular}{l|l}
3.35 & 1.28
\end{tabular}

$2.80 \quad 1.15$

$3.53 \quad 0.99$

$4.03 \quad 0.67$

$3.64 \quad 0.89$

20. There can be little action taken here until a supervisor approves the decision.

21. In the implementation of QS-9000, a steering committee has been formed.

22. QS-9000 registration is not primarily the responsibility of the Quality Department.

23. During problem solving sessions, we make an effort to get team members' opinions and ideas before making a decision.

24. Managers here try to plan ahead for changes associated with QS-9000 that might affect our performance.

25. Generally, to meet the QS-9000 registration requirement, we have redesigned jobs and processes.

26. I have face-to-face discussions with management about QS-9000 registration.

27. In general, supervisors place trust in the employees' abilities to perform their job well.

28. Generally, we use statistical methods to check on the quality of our work.

$2.98 \quad 1.04$

$3.84 \quad 0.94$

2.97

0.97

3.92

$2.92 \quad 1.46$

1.11

4.00

0.67

29. Supervisors often fail to give feedback on the work that is well done in participating in QS-9000 teams.

30. My manager regularly recognizes the quality of my work.

31. Senior management uses QS-9000 to develop the overall business strategy.

32. Generally, we use self-directed work teams to support our quality efforts.

33. We encourage our employees to focus on customer requirements.

34. Quality goals and objectives relating to QS-9000 are included as a part of the strategic business plan.

35. As a result of QS-9000, our delivery performance has improved.

36. After we completed QS-9000 registration, our overall quality parts per million (PPM) were reduced.

37. Our customer satisfaction level has improved since completing QS-9000 registration.

38. We have experienced sales growth as a result of our QS-9000 registration.

39. As a result of QS-9000, we have reduced our overall costs. 
the second study, and five additional companies were randomly selected to replace prior respondents.

Although the automotive supply parts industry is considered an industry of its own, the diversity of products supplied has an impact on the quality management systems implemented to achieve QS-9000. This may cause some variability in responses to certain questions. Size is another issue that could cause variability.

The key informant for this study primarily consisted of individuals who are responsible for quality management within their organization and hold positions as quality manager, director of quality, and QS-9000 coordinator, to name a few. These professionals are the most knowledgeable and reliable sources regarding the organizational variables and impacts on performance measurements associated with pursing certification to a quality standard.

\section{Internal Consistency}

Cronbach's alpha (or coefficient alpha) is the most popular of the internal consistency coefficients and reliability. The generally agreed-upon lower limit for Cronbach's alpha is .70 (Robinson, Shaver, and Wrightsman 1991; Robinson and Shaver 1973). Through this item analysis, all factors were individually analyzed and calculated alpha values are greater than .70 (see Table 3), meaning there is internal consistency of each factor. After the summated scale (factor) has been analyzed for reliability to ensure appropriateness, the next step is to assess validity.

\section{Validation of the Questionnaire}

Initially interviews were conducted at a large tier-one automotive supplier directly owned by an OEM with two quality managers, a QS-9000 coordinator, an hourly quality technician, and six production operators participating. From the interviews and through the literature reviews, an initial survey document was developed. Before the initial survey questionnaire was sent to respondents, it was pretested/piloted by 10 quality directors and managers from a tier-one automotive supplier for construct validity. Some of the questions were reworded for clarity, a couple of questions were deleted, and, finally, a few questions were added.

The validity of the survey document was also confirmed by conducting a $\mathrm{t}$-test of the sample means of each question at an alpha level of 0.05 to identify any significant differences. Between the two samples, there were no statistically significant differences on any of the 34 original questions. 